Campos Neutrais - RevistaLatino-Americana de Relações Internacionais Vol. 1, No 2, p. 73-90, Maio - Agosto de 2019

\title{
A diversidade da agricultura urbana e periurbana em Presidente Prudente - SP
}

\author{
Antonio Nivaldo Hespanhol ${ }^{1}$ \\ Claudinei da Silva Pereira ${ }^{2}$ \\ Rosangela Aparecida de Medeiros Hespanhol ${ }^{3}$
}

Resumo: O objetivo do artigo foi analisar a diversidade da agricultura urbana e periurbana em Presidente Prudente, tomando como referência a dimensão das áreas cultivadas, os tipos de terrenos, os sistemas de produção e os canais de comercialização utilizados.Foram identificadas e mapeadas as áreas hortícolas e as ocupadas com outros tipos de cultivo; entrevistas com técnicos e dirigentes municipais foram realizadas e um formulário foi aplicado a 23 horticultores. Constatou-se que 56,5\% dos horticultores pesquisados cultivam áreas próprias cujas dimensões são inferiores a dois mil metros quadrados, sendo que 87,0\% empregam sistemas convencionais de cultivo. Os $91,3 \%$ dos produtores pesquisados que comercializam a produção, o fazem por intermédio de feiras livres, sacolões, mercados de bairro e da venda direta aos consumidores. Conclui-se que a AUP é resiliente e tem sido importante na composição da renda dos produtores e no abastecimento de produtos hortícolas de alta perecibilidade.

Palavras-chave: agricultura urbana e periurbana, horticultura, cidade.

\section{The diversity of urban and peri-urban agriculture \\ in Presidente Prudente, SP}

\begin{abstract}
The purpose of this article was to analyze the diversity of urban and peri-urban agriculture in Presidente Prudente, taking as reference the size of cultivated areas, land types, production systems, and marketing channels used. Horticultural areas and areas occupied with other types of cultivation were identified and mapped; interviews were carried out with technicians and municipal leaders; and a form was applied to 23 horticulturists. It was observed that $56.5 \%$ of the horticulturists surveyed cultivate their own areas, which have less than two thousand square meters in area, $87.0 \%$ of which use conventional cultivation
\end{abstract}

\footnotetext{
1 Diretor-Presidente da Fundação VUNESP e professor dos cursos de Graduação e de Pós-Graduação em Geografia da Universidade Estadual Paulista Júlio de Mesquita Filho, Campus de Presidente Prudente - SP.

2 Doutorando pela Faculdade de Ciências e Tecnologia da UNESP, Câmpus de Presidente Prudente.

3 Professora assistente doutora do Departamento de Geografia da Faculdade de Ciências e Tecnologia da UNESP de Pres. Prudente.
} 
systems. $91.3 \%$ of the producers surveyed that market their production, do it through open-air markets, produce markets, neighborhood markets, and direct sales to consumers. It is concluded that UPA is resilient and has been important in the composition of income of producers and in the supply of vegetables of high perishability.

Keywords: Urban and peri-urban agriculture, horticulture, city.

\section{Introdução}

A agricultura urbana e periurbana (AUP) vêm ganhando importância no mundo e no Brasil. Para a compreensão de sua dinâmica, é necessário entender o processo de expansão territorial das cidades decorrente da atuação de diferentes agentes, dentre os quais se destacam os incorporadores imobiliários e o poder público: os primeiros promovem o parcelamento de glebas em lotes urbanos e o segundo regulamenta e disciplina o uso do solo urbano.

A AUP ganhou expressividade em diversos países em decorrência de crises econômicas e guerras, mas passou a se expandir também devido à atuação de grupos que estimulam a interação social de vizinhança, a produção local de alimentos frescos e saudáveis, por meio da qual é possível ampliar a segurança alimentar e melhorar a qualidade do ambiente urbano, além do reaproveitamento de resíduos orgânicos.

O principal objetivo do artigo foi analisar a diversidade da AUP em Presidente Prudente, município localizado no oeste do Estado de São Paulo. Foram adotados os seguintes procedimentos metodológicos: a) revisão bibliográfica sobre AUP; b) identificação e mapeamento das áreas de ocorrência da AUP em Presidente Prudente; c) realização de entrevistas com técnicos e dirigentes vinculados à Secretaria de Desenvolvimento Econômico de Presidente Prudente; d) aplicação de formulário a 23 produtores. No formulário utilizado para a realização da pesquisa com os produtores urbanos e periurbanos foram abordados os seguintes temas: a) dimensão das áreas cultivadas; b) tipos de terrenos em que são praticados os cultivos e condições de acesso a eles; c) sistemas de produção adotados; d) produtos cultivados; e) canais de comercialização utilizados.

\section{Diversidade e resistência da AUP em diferentes contextos}

Por localizar-se no interior do tecido urbano ou nas suas imediações, a AUP disputa espaço pelo uso do solo com os proprietários de terrenos privados e os agentes que atuam no mercado imobiliário. A expectativa seria a de que com o incremento do preço da terra houvesse o recuo da AUP, mas essa atividade tem sido resiliente, ainda que as áreas nas quais 
o cultivo costuma ser realizado mudem com frequência, devido à conversão nos usos do solo, notadamente com o parcelamento de glebas ou edificação nos lotes onde eram realizados os plantios.

A AUP apresenta grande diversidade, havendo desde a produção destinada ao autoconsumo familiar até os cultivos essencialmente comerciais, os quais costumam ser mais intensivos em capital e com maior inserção nos mercados. No entanto, entre esses dois extremos há outras possibilidades de AUP, conforme demonstram os estudos desenvolvidos por Mougeot (2000) e Madaleno (2001).

Apesar da tendência ao alargamento dos circuitos produtivos imposta pelo desenvolvimento capitalista, alguns fatores concorrem para a permanência e resistência da AUP. De acordo com Silva (2009), ainda que a elevação do preço da terra exerça forte pressão sobre a AUP, mesmo assim ela resiste, em razão dos seguintes fatores: a) maior proximidade do mercado consumidor; b) disponibilidade de uma rede de estradas e de infraestruturas de acesso; c) facilidade de acesso aos equipamentos de distribuição e armazenagem. A resiliência da AUP também tem sido favorecida porque uma parcela crescente de consumidores tem preferido os alimentos saudáveis cultivados localmente e livres de agrotóxicos (SILVA, 2009).

Machado e Machado (2002) ressaltam que o cultivo de hortaliças, legumes, frutas e plantas medicinais nos espaços urbanos e periurbanos pode favorecer a formação de microclimas, possibilitar uma alimentação mais diversificada e disponibilizar medicamentos alternativos, prevenindo doenças e melhorando a qualidade de vida das pessoas que têm acesso a esses produtos. Assim, a AUP pode gerar efeitos positivos sobre o ambiente e a qualidade de vida nas cidades porque ocupa espaços ociosos, o que contribui para reduzir o acúmulo de lixo em terrenos baldios e mantém as áreas com cobertura vegetal, permitindo a infiltração de água nos solos.

De acordo com Drescher (2000), dois princípios têm guiado as experiências em AUP: 1) o direito humano de produzir alimentos; 2) o direito humano de acesso aos recursos naturais, podendo qualquer cidadão cultivar a terra ociosa, sem que esse cultivo diminua o valor do imóvel para o proprietário. Esses dois princípios, no entanto, nem sempre são observados pelos agentes imobiliários e proprietários de terrenos baldios, assim como pelo poder público.

No caso brasileiro, não obstante a importância e a relevância da AUP, não há políticas públicas contínuas que a estimulem ou protejam. Os agricultores urbanos e periurbanos raramente possuem a Declaração de Aptidão ao PRONAF (DAP), embora desde 2014 esse 
Campos Neutrais - RevistaLatino-Americana de Relações Internacionais Vol. 1, No 2, p. 73-90, Maio - Agosto de 2019

documento possa ser emitido desde que tais produtores atendam aos requisitos exigidos para o enquadramento como agricultores familiares, conforme estabelece a Portaria $\mathrm{n}^{\mathbf{o}} 21$ do então Ministério do Desenvolvimento Agrário (MDA).

A Secretaria Especial de Agricultura Familiar e do Desenvolvimento Agrário, por meio da Portaria $n^{\circ}$ 234, de 04 de abril de 2017, estabeleceu as condições e procedimentos gerais para a emissão da DAP, considerando que a Unidade Familiar de Produção Rural deve ser identificada com a produção agropecuária, não importando se a localização se dá em ambiente estritamente rural ou urbano, tendo, no entanto, que atender aos requisitos exigidos para o enquadramento como agricultor familiar, conforme definido pela Lei $\mathrm{n}^{\mathbf{0}} 11.326$, de 2006, que estabelece as diretrizes para a formulação da Política Nacional da Agricultura Familiar e Empreendimentos Familiares Rurais.

Os requisitos necessários para o enquadramento como agricultor familiar são os seguintes: a) não deter área superior a quatro módulos fiscais; b) utilizar predominantemente mão de obra da própria família; c) ter como principal fonte de renda as atividades desenvolvidas no estabelecimento; d) dirigir o estabelecimento com sua família.

Os agricultores urbanos e periurbanos normalmente possuem outras fontes de renda, com destaque para a aposentadoria, não atendendo todos os requisitos exigidos para serem enquadrados como agricultores familiares a fim de obter a Declaração de Aptidão ao PRONAF (DAP). Mesmo os que se encontram habilitados a solicitá-la, na maioria das vezes acabam não a requerendo por não estarem cientes dessa possibilidade.

A DAP, além de propiciar acesso ao Programa Nacional de Fortalecimento da Agricultura Familiar (PRONAF), que disponibiliza crédito agrícola oficial em condições mais favoráveis do que as vigentes no mercado financeiro, também possibilita a venda dos produtos ao Programa de Aquisição de Alimentos (PAA) e/ou Programa Nacional de Alimentação Escolar (PNAE).

No período compreendido entre 2003 e 2010, o Ministério do Desenvolvimento Social (MDS) implementou ações de Segurança Alimentar e Nutricional (SANS) e estimulou o fortalecimento das experiências preexistentes de AUP. A despeito do esforço do governo federal em valorizar e fortalecer essa atividade, a grande maioria dos governos municipais não se envolveu, nem deu o apoio esperado.

$\mathrm{Na}$ verdade, a ação dos municípios no apoio à agricultura em geral e à AUP, em particular, sempre foi muito limitada, sendo que a grande maioria sequer reconhece a AUP como um fenômeno importante e que demanda apoio e regulamentação para que possa ser 
Campos Neutrais - RevistaLatino-Americana de Relações Internacionais Vol. 1, No 2, p. 73-90, Maio - Agosto de 2019

praticada em consonância com os planos urbanísticos das cidades e com os planos diretores dos municípios. Tais planos, quando existem, normalmente ignoram a existência da AUP e a entendem mais como um empecilho do que como um fenômeno positivo a ser contemplado no planejamento e gestão urbanos.

Há no país experiências pontuais de reconhecimento e apoio à AUP e elas se limitam a algumas áreas metropolitanas, como as de Belo Horizonte, Curitiba, Goiânia, Porto Alegre, São Paulo e Belém, conforme evidenciado por Santandreu e Lovo (2007).

No ano de 2018 foi instituído, por meio da Portaria 467, de 7 de fevereiro de 2018, o Programa Nacional de Agricultura Urbana e Periurbana, com o intuito de formalizar parcerias na perspectiva de promover a agricultura urbana, na forma de produção agrícola sustentável, comunitária e/ou doméstica, por meio da introdução de tecnologias de produção sustentáveis como catalizador da segurança alimentar, geração de renda e inclusão social.A dotação orçamentária do Programa foi de apenas 1,9 milhão de reais, destinada à compra de sementes e equipamentos para a construção de hortas, segundo informações do então Ministério do Desenvolvimento Social (MDS). No mesmo ano, o Estado de Santa Catarina instituiu a Política Estadual de Apoio à Agricultura Urbana, por meio daLei no 17.533 , de 19 de junho de 2018. No ano anterior (2017), foi criado o Programa Municipal de Agricultura Urbana de Florianópolis, por meio do Decreto nº 17.688, de 05 de junho de 2017.

Em Presidente Prudente não há programa nem dispositivos legais que regularizem a AUP, mas o fenômeno é expressivo, conforme se procurará demonstrar no item subsequente.

\section{Diversidade da agricultura urbana e periurbana em Presidente Prudente}

O município de Presidente Prudente está localizado no oeste do Estado de São Paulo, a $560 \mathrm{~km}$ da capital, como se verifica na Figura 1.

Presidente Prudente é a sede da Região Administrativa homônima, composta por 53 municípios. Em 2010, o município apresentava uma população de 207.610 habitantes, com 200.132 (96,3\%) vivendo na cidade de Presidente Prudente, de acordo com os dados do Censo Demográfico do Instituto Brasileiro de Geografia e Estatística (IBGE). A cidade concentra atividades comerciais e serviços especializados que atendem a população regional (LEITE, 1972), além de contar com a representação regional de vários órgãos das administrações públicas estadual e federal, o que lhe confere elevada centralidade. 
Campos Neutrais - RevistaLatino-Americana de Relações Internacionais Vol. 1, No 2, p. 73-90, Maio - Agosto de 2019

FIGURA 1 - Localização de Presidente Prudente no Estado de São Paulo

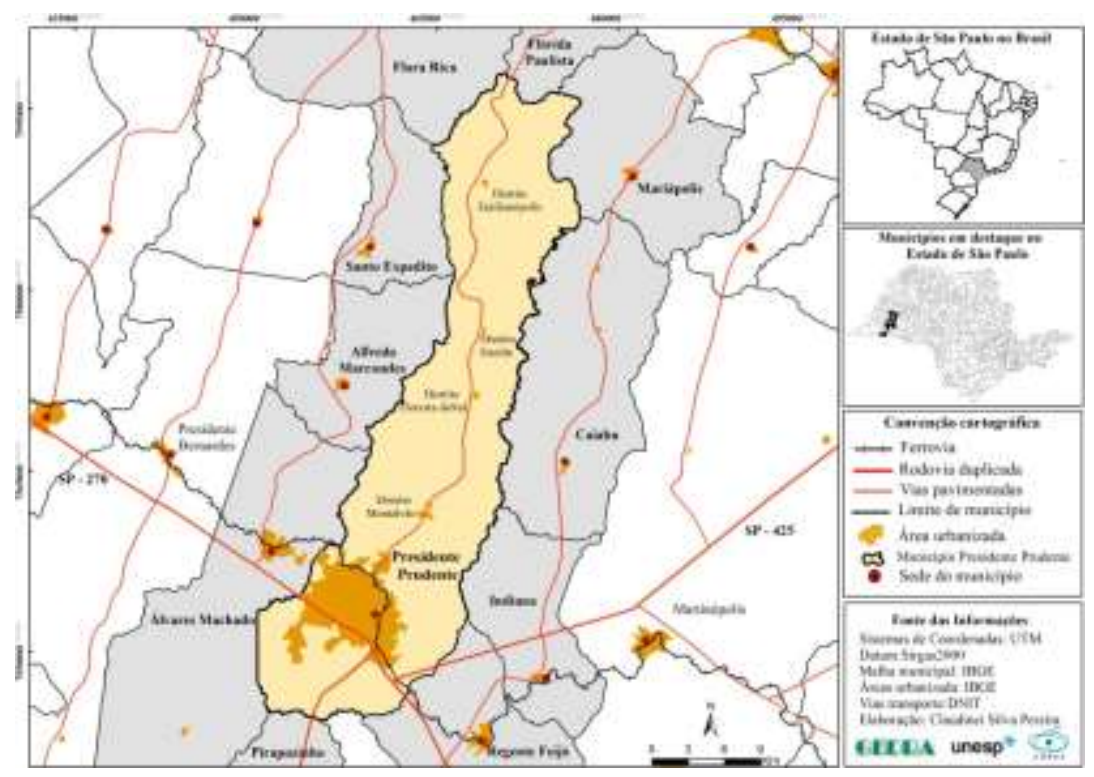

Fonte: Sistemas de Coordenadas UTM

A polarização de Presidente Prudente se explica pelo fato de ser a única cidade de porte médio num raio de aproximadamente 200 quilômetros. Marília, que possui funções urbanas semelhantes às de Presidente Prudente se situa a 180 quilômetros, enquanto Londrina e Maringá, maiores e mais dinâmicas que Presidente Prudente, estão a cerca de 170 quilômetros e se situam no Estado do Paraná.

Do ponto de vista da produção do espaço urbano em Presidente Prudente, é significativa a implantação, pelos agentes imobiliários, de bairros residenciais direcionados à população de médio e alto poder aquisitivo, inclusive com a instituição de loteamentos fechados. A zona sul da cidade, por exemplo, vem se consolidando como um vetor de expansão seletiva de loteamentos fechados de alto padrão, com destaque para a atuação do Grupo Encalso Damha e da Incorporadora Mampei Funada. Estas incorporadoras dispõem de glebas não loteadas nessa porção do município, as quais poderão ser utilizadas para o estabelecimento de novos empreendimentos imobiliários no momento em que julgarem pertinente. Noutras áreas da cidade também foram implantados loteamentos fechados, por outras incorporadoras, sendo alguns direcionados a segmentos populacionais com rendimento médio e baixo.

As incorporadoras imobiliárias, ao fazerem o loteamento de glebas, e o poder público, ao redefinir o perímetro urbano, estabelecer o zoneamento funcional da cidade, implantar vias de circulação e dotar as diferentes áreas de infraestrutura e serviços públicos básicos, exercem, juntos, forte influência sobre o processo de expansão urbana.

Loteamentos foram realizados em áreas afastadas da malha urbana de Presidente 
Campos Neutrais - RevistaLatino-Americana de Relações Internacionais Vol. 1, No 2, p. 73-90, Maio - Agosto de 2019

Prudente, o que resultou numa cidade dispersa, desigual e fragmentada, conforme salientam Sposito e Góes (2013).

A expansão urbana, no contexto contemporâneo, em que a mobilidade espacial propiciada pela maior facilidade de acesso aos meios de transporte individual, associada à fragilidade do poder público municipal em planejar e regular a produção da cidade, acaba privilegiando os agentes imobiliários e os detentores de glebas ainda não parceladas.

O interesse tanto de incorporadores como de proprietários fundiários na apropriação da renda da terra resultam na coexistência de espaços já loteados e parcelados e de glebas ainda não parceladas que se localizam no interior da área urbana consolidada e no seu entorno imediato, gerando não somente uma cidade dispersa, mas também uma vasta zona de transição entre a cidade e o campo, cujos usos são bastante diferenciados. Há propriedades com características rurais incrustradas entre bairros urbanizados e áreas que foram anexadas ao perímetro urbano, onde foram implantados loteamentos fechados descontínuos ao tecido urbano, assim como chácaras, cujos usos são variados, mas que foram parceladas como áreas urbanas, em consonância e/ou divergência com o estabelecido no plano urbanístico de Presidente Prudente aprovado no ano de 2008.

Dessa forma, o mapeamento da agricultura urbana e periurbana possibilita compreender a dinâmica da produção do espaço urbano em termos de conteúdos e finalidades, sendo os chamados vazios urbanos uma das formas resultantes dessa dinâmica (VILLAÇA, 2001; VALE, 2005; NASCIMENTO, 2014). Tais vazios urbanos normalmente são ocupados por pastagens, permanecem improdutivos ou são utilizados para a realização de cultivos agrícolas destinados ao autoconsumo e/ou à comercialização.

Na Figura 2 são indicados os principais usos do solo na área periurbana e no entorno da cidade de Presidente Prudente.

O uso do solo nas áreas situadas no entorno da cidade é heterogêneo, embora predominem pastagens, vegetações arbustivas e remanescentes florestais. Usos institcionais também estão presentes, tais como o aeroporto, o distrito industrial, o hospital psiquiátrico, o parque ecológico, o lixão, assim como os loteamentos de chácaras. 
Campos Neutrais - RevistaLatino-Americana de Relações Internacionais Vol. 1, No 2, p. 73-90, Maio - Agosto de 2019

FIGURA 2 - Presidente Prudente: Uso do solo urbano e periurbano

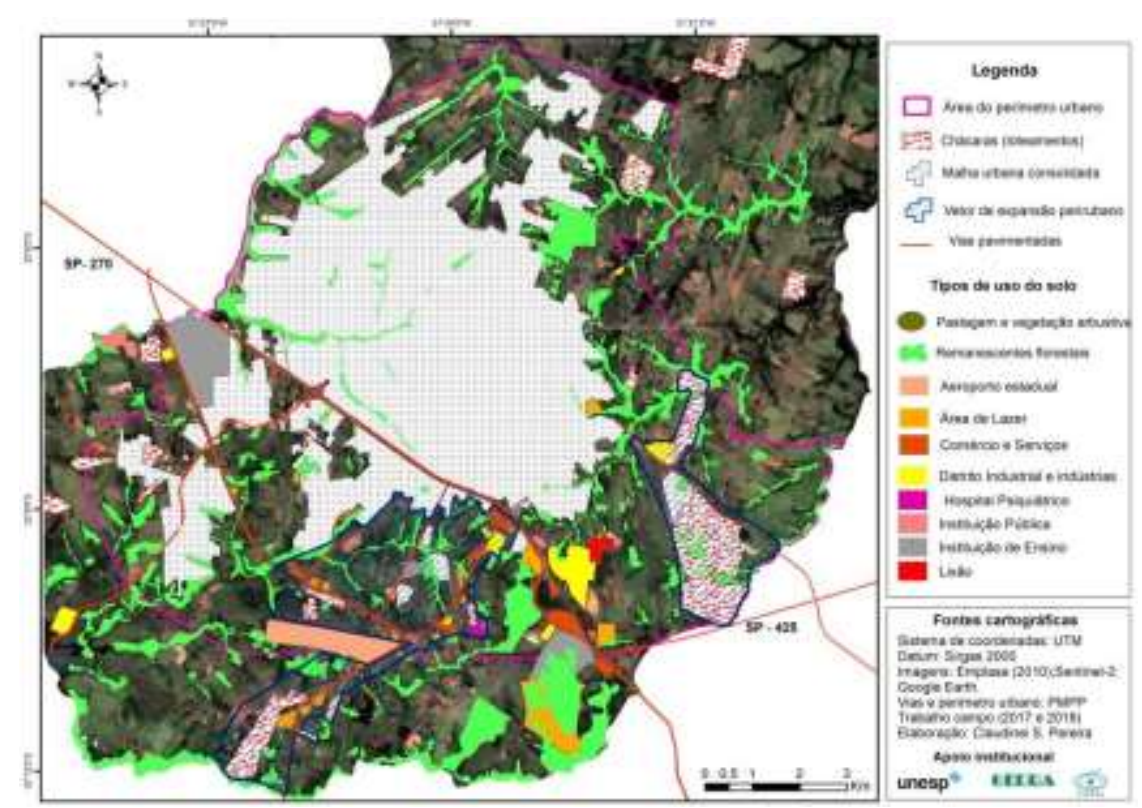

Fonte: Sistemas de Coordenadas UTM

A superfície total das propriedades onde são realizados os cultivos dos 23 agricultores urbanos e periurbanos pesquisados é de 1.363.250 metros quadrados, o que equivale a pouco mais de 136 hectares. Verifica-se, na Tabela 1, a correlação entre a dimensão das propriedades e o número de produtores. Entre os 23 pesquisados, onze (47,8\% do total) dispõem de áreas inferiores a um hectare (10.000 metros quadrados), considerando inclusive as áreas construídas, enquanto nove (39,1\% do total) arrendam ou detêm propriedades que variam de um a 10 hectares e apenas três $(13,0 \%$ do total) possuem ou arrendam áreas cujas dimensões ultrapassam 10 hectares e se situam em áreas periurbanas ainda não loteadas.

TABELA 1 - Dimensão das propriedades em que os agricultores urbanos e periurbanos pesquisados realizam os cultivos em Presidente Prudente - SP

\begin{tabular}{l|c|c|c}
\hline \multicolumn{1}{c|}{$\begin{array}{c}\text { Área } \\
\left(\mathrm{Em} \mathrm{m}^{2}\right)\end{array}$} & $\begin{array}{c}\mathrm{N}^{\mathbf{o}} \mathrm{de} \\
\text { produtores }\end{array}$ & $\begin{array}{c}\% \\
\text { produtores }\end{array}$ & $\begin{array}{c}\text { Área } \\
\text { total }\left(\mathrm{m}^{2}\right)\end{array}$ \\
\hline Até 500 & 6 & 26,0 & 1.500 \\
\hline 501 a 1.000 & 0 & 0 & 0 \\
\hline 1.001 a 5.000 & 3 & 13,0 & 8.050 \\
\hline 5.001 a 9.999 & 2 & 8,8 & 14.100 \\
\hline 10.000 a 20.000 & 2 & 8,8 & 26.600 \\
\hline 20.001 a 100.000 & 7 & 30,4 & 333.000 \\
\hline Acima de 100.000 & 3 & 13,0 & 980.000 \\
\hline Total & 23 & & 1.363 .250 \\
\hline
\end{tabular}


Campos Neutrais - RevistaLatino-Americana de Relações Internacionais Vol. 1, No 2, p. 73-90, Maio - Agosto de 2019

FONTE: Pesquisa de campo realizada no mês de junho de 2017

A superfície efetivamente cultivada pelos 23 agricultores pesquisados é de 129.070 metros quadrados, o equivalente a menos de 13 hectares. Verifica-se, na Tabela 2, que onze (47,8\% do total) agricultores pesquisados cultivam em áreas inferiores a 1.000 metros quadrados, dois (8,7\% do total), em áreas cujas superfícies variam de um a dois mil metros quadrados, e dez (43,5\% do total), em áreas superiores a dois mil metros quadrados.

TABELA 2 - Dimensão das áreas utilizadas para os cultivos dos produtores pesquisados em Presidente Prudente

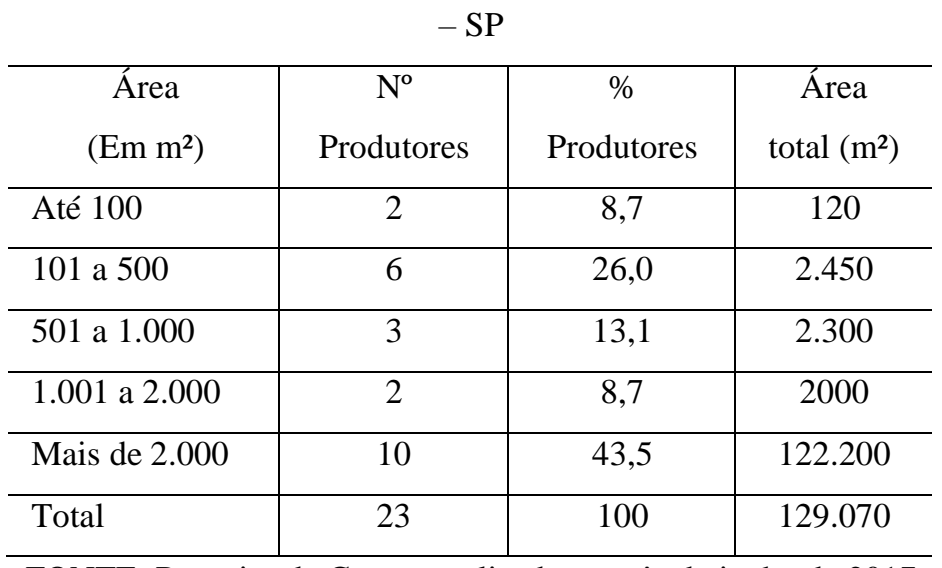

FONTE: Pesquisa de Campo realizada no mês de junho de 2017

Dos agricultores pesquisados, nove $(39,1 \%)$ cultivam em áreas ainda não incorporadas à malha urbana e $14(60,9 \%)$ se situam no perímetro urbano, sendo que quatro cultivam em chácaras, cinco, em terrenos não edificados, três, em quintais, e dois, em áreas públicas, conforme se verifica na Tabela 3 . 
Campos Neutrais - RevistaLatino-Americana de Relações Internacionais Vol. 1, No 2, p. 73-90, Maio - Agosto de 2019

TABELA 3 - Tipos de terrenos em que são realizados os cultivos pelos agricultores urbanos e periurbanos pesquisados em Presidente Prudente - SP

\begin{tabular}{l|c|c}
\hline \multicolumn{1}{c|}{ Tipo de terreno } & $\begin{array}{c}\mathrm{N}^{\circ} \mathrm{de} \\
\text { Produtores }\end{array}$ & $\begin{array}{c}\% \mathrm{de} \\
\text { produtores }\end{array}$ \\
\hline Propriedades rurais & 9 & 39,1 \\
\hline Terreno não edificado & 5 & 21,7 \\
\hline Lotes em chácaras & 4 & 17,4 \\
\hline Quintal de residência & 3 & 13,1 \\
\hline Área pública municipal & 2 & 8,7 \\
\hline Total & 23 & 100 \\
\hline
\end{tabular}

FONTE: Pesquisa de campo realizada no mês de junho de 2017

Os agentes responsáveis pela implantação dos loteamentos de chácaras ficam incumbidos de implantar a infraestrutura urbanística, e os proprietários das chácaras devem cumprir as normas para edificação vigentes no município.

No que concerne às condições de acesso à terra, mais de $50 \%$ das áreas cultivadas pelos pesquisados são próprias ou pertencem às suas famílias, sendo as demais arrendadas e concedidas, conforme se verifica na Tabela 4.

TABELA 4 - Condições de acesso às áreas cultivadas pelos agricultores urbanos e periurbanos pesquisados em Presidente Prudente - SP

\begin{tabular}{l|c|c}
\hline Condição & $\begin{array}{c}\mathrm{N}^{\circ} \mathrm{de} \\
\text { Produtores }\end{array}$ & $\begin{array}{c}\% \text { de } \\
\text { produtores }\end{array}$ \\
\hline Área própria pertencente à família & 14 & 60,8 \\
\hline Área concedida & 3 & 13,1 \\
\hline Área arrendada & 3 & 13,1 \\
\hline Área pública concedida & 2 & 8,7 \\
\hline Área alugada & 1 & 4,3 \\
\hline Total & 23 &, 0 \\
\hline
\end{tabular}

FONTE: Pesquisa de Campo realizada no mês de junho de 2017

As condições de acesso às áreas utilizadas pelos agricultores urbanos e periurbanos evidenciam como a terra rural e urbana, convertida em mercadoria, continua sendo restrita do ponto de vista social e produtivo.

Verifica-se, na Tabela 5, que vinte $(87,0 \%$ do total) dos agricultores entrevistados adotam sistemas convencionais de produção, e apenas três (13,0\% do total) utilizam outros sistemas: dois são produtores orgânicos e um utiliza o sistema hidropônico. 
Campos Neutrais - RevistaLatino-Americana de Relações Internacionais Vol. 1, $\mathrm{N}^{\mathrm{O}}$ 2, p. 73-90, Maio - Agosto de 2019

TABELA 5 - Sistemas de produção utilizados pelos agricultores urbanos e periurbanos pesquisados em

\begin{tabular}{l|c|c}
\multicolumn{3}{c}{ Presidente Prudente - SP } \\
\hline $\begin{array}{c}\text { Sistema de } \\
\text { produção }\end{array}$ & $\begin{array}{c}\mathrm{N}^{\mathrm{o}} \mathrm{de} \\
\text { Produtores }\end{array}$ & $\begin{array}{c}\% \text { de } \\
\text { produtores }\end{array}$ \\
\hline Convencional & 20 & 87,0 \\
\hline Orgânica & 2 & 8,7 \\
\hline Hidropônica & 1 & 4,3 \\
\hline Total & 23 &, 0 \\
\hline
\end{tabular}

FONTE: Pesquisa de campo realizada no mês de junho de 2017

Um dos produtores pesquisados implantou uma empresa que produz e comercializa produtos orgânicos. Trata-se de um estabelecimento sofisticado que fornece produtos personalizados e visa a atender clientes com maior poder aquisitivo. No estabelecimento, situado no Jardim Paulista, um bairro de classe média em Presidente Prudente, o cliente pode observar a área de produção, pois a horta é contígua e está integrada à loja.

Outro produtor de folhosas e legumes orgânicos também possui uma pequena loja, na qual, além dos produtos de cultivo próprio, comercializa outros produtos orgânicos procedentes de outros produtores, tais como mel, produtos lácteos, açúcar, carnes e mesmo hortaliças.

Um terceiro produtor utiliza o sistema hidropônico e implantou a empresa "Viva Verde", que se situa no entorno do bairro Humberto Salvador. O capital é de origem familiar, advindo da associação de dois irmãos, e a empresa conta com quatro funcionários. A área total da propriedade é de 29 hectares e ainda não foi parcelada, sendo mantida como área rural incrustrada no espaço urbano. A área se situa entre o Parque Watal Ishibashi e o Jardim Humberto Salvador, dois bairros populares com elevada densidade demográfica, situados na zona norte da cidade.A horta ocupa apenas 10.000 metros quadrados e nela estão instaladas trinta estufas para o cultivo hidropônico de hortaliças de folhagens. Possui berçário, onde é produzida a maior parte das mudas, sendo o restante adquirido do Viveiro de Mudas Brambilla, localizado no município de Piacatu (SP), a 150 quilômetros de Presidente Prudente.

A família do produtor pesquisado adquiriu a propriedade no ano de 1974, onde, no passado, se plantavam algodão, amendoim, feijão e outras lavouras, além da criação de gado bovino. De acordo com o entrevistado, em virtude de a propriedade atualmente estar situada na borda da malha urbana, alguns corretores e empresas do setor imobiliário já manifestaram 
Campos Neutrais - RevistaLatino-Americana de Relações Internacionais Vol. 1, $\mathrm{N}^{\mathrm{O}}$ 2, p. 73-90, Maio - Agosto de 2019

interesse em negociá-la ou comprá-la, mas o entrevistado, que é o patriarca da família, afirmou que a atividade hortícola está dando bom retorno econômico e que, no momento, não pretende vendê-la. No entanto, ele considera que a tendência, no futuro, é que pelo menos parte da área seja vendida, pois a superfície efetivamente utilizada para a produção se restringe aos dez mil metros quadrados onde estão instaladas as estufas.

A exploração produtiva do restante da propriedade, segundo o entrevistado, é inviável. Como a área está no limite do tecido urbano, as cercas são rompidas com muita frequência, o que inviabiliza a criação de animais. Também há dificuldades para realizar cultivos agrícolas, porque a família não dispõe de mão de obra suficiente e não compensa utilizar força de trabalho externa, em virtude do seu elevado custo.

Nas trinta estufas são produzidos, em média, trinta mil maços de folhosas por mês, e grande parte dessa produção é vendida para a loja da rede de atacados Assaí e aos supermercados Nagai, Pastorinho e Estrela, todos localizados na própria cidade de Presidente Prudente. Os produtos também são vendidos a ambulantes que os revendem em domicílio e/ou em diferentes pontos instalados em vias públicas da cidade.

Em relação à produção de horta em área urbana, destaca-se a localizada no bairro Brasil Novo, que ocupa 7.500 metros quadrados, sendo o que restou do Programa "Alimente Prudente", criado pela municipalidade no ano de 1997. Essa política pública municipal incentivou a prática da agricultura urbana, por meio da doação de sementes, prestação de assistência técnica, disponibilização do acesso à água para irrigação e do fornecimento gratuito de esterco de galinha, gado e casca de amendoim. Em contrapartida, a prefeitura exigia que parte dos alimentos produzidos nas hortas em áreas públicas e por ela apoiadas fosse doada às escolas e creches municipais.

De acordo com o único produtor que ainda realiza os cultivos na área, a prefeitura abandonou o projeto no ano de 2005 , e as sete famílias que cultivavam no lote tiveram que arcar com os custos da produção, levando-as a deixar o projeto. Além dos elevados custos, as dificuldades de acesso à água para irrigação foram decisivas para desencorajar as seis famílias, que acabaram vendendo o "direito" de sua exploração na área pública municipal ao único produtor remanescente que, já idoso, continua cultivando no local, com o auxílio de um filho e de dois sobrinhos.

O produtor cultiva dezenas de canteiros, mas normalmente mantém metade da área em produção, devido à restrita disponibilidade de água para irrigação. Foram perfurados quatro poços "caipiras" para irrigar os canteiros, mas a quantidade de água é insuficiente, sobretudo 
Campos Neutrais - RevistaLatino-Americana de Relações Internacionais Vol. 1, No 2, p. 73-90, Maio - Agosto de 2019

no período entre abril e setembro, quando os índices pluviométricos são menores na região de Presidente Prudente, ocasionando o rebaixamento do nível do lençol freático.

A comercialização é feita, diretamente, aos consumidores que residem no Conjunto Habitacional Brasil Novo e em bairros vizinhos, no ponto de venda situado na própria área onde é realizada a produção. São cultivados na referida área: almeirão, salsinha, cebolinha, couve, rúcula, alface (crespa, lisa, mimosa), agrião, coentro, brócolis, feijão de corda, mandioca e rabanete. As mudas são adquiridas do vendedor do Viveiro de Mudas Brambilla.

A maioria dos agricultores pesquisados dispõe de pouco capital, e a comercialização dos produtos tem a função principal de complementar a renda familiar. Apenas dois agricultores pesquisados ( $8,7 \%$ do total) cultivam principalmente para o autoconsumo.

Os cultivos realizados pelos agricultores são diversos em termos de tipos de folhagens e de hortaliças de frutos, raízes e tubérculos, conforme se verifica nas Tabelas 6 e 7.

Dos 23 agricultores, $22(95,6 \%)$ produzem folhagens, sendo que 11 produzem também hortaliças de frutos, raízes e tubérculos em determinadas épocas do ano. Apenas um produtor $(4,4 \%)$ não produz folhagens, dedicando-se exclusivamente ao cultivo de quiabo.

TABELA 6 - Tipos de folhagens cultivadas pelos agricultores urbanos e periurbanos pesquisados em Presidente

\begin{tabular}{l|c|c}
\multicolumn{3}{c}{ Prudente $-\mathrm{SP}$} \\
\hline \multicolumn{1}{c|}{ Tipo } & $\begin{array}{c}\mathrm{N}^{\circ} \text { de } \\
\text { Produtores }\end{array}$ & $\begin{array}{c}\% \text { de } \\
\text { produtores }\end{array}$ \\
\hline Alface & 21 & 91,3 \\
\hline Cebolinha & 21 & 91,3 \\
\hline Couve & 21 & 91,3 \\
\hline Salsinha & 19 & 82,6 \\
\hline Coentro & 17 & 73,9 \\
\hline Almeirão & 16 & 69,5 \\
\hline Rúcula & 15 & 65,2 \\
\hline Brócolis & 9 & 39,1 \\
\hline Espinafre & 7 & 30,4 \\
\hline Agrião & 5 & 21,7 \\
\hline Chicória & 4 & 17,4 \\
\hline Repolho & 4 & 17,3 \\
\hline Hortelã & 2 & 8,7 \\
\hline Acelga & 1 & 4,3 \\
\hline
\end{tabular}

FONTE: Pesquisa de Campo realizada no mês de junho de 2017 
Campos Neutrais - RevistaLatino-Americana de Relações Internacionais Vol. 1, No 2, p. 73-90, Maio - Agosto de 2019

TABELA 7 - Tipos de hortaliças de frutos, raízes e tubérculos cultivadas pelos agricultores urbanos e periurbanos pesquisados em Presidente Prudente - SP

\begin{tabular}{l|c|c|}
\hline \multicolumn{1}{c|}{ Tipo } & $\begin{array}{c}\mathrm{N}^{\circ} \mathrm{de} \\
\text { Produtores }\end{array}$ & $\begin{array}{c}\% \mathrm{de} \\
\text { produtores }\end{array}$ \\
\hline Mandioca & 5 & 21,7 \\
\hline Chuchu & 3 & 13,1 \\
\hline Abóbora & 2 & 8,7 \\
\hline Abobrinha & 2 & 8,7 \\
\hline Berinjela & 2 & 8,7 \\
\hline Jiló & 2 & 8,7 \\
\hline Quiabo & 2 & 8,7 \\
\hline Rabanete & 2 & 8,7 \\
\hline Pimentão & 1 & 4,3 \\
\hline Tomate & 1 & 4,3 \\
\hline
\end{tabular}

FONTE: Pesquisa de Campo realizada no mês de junho de 2017

No que concerne à venda dos produtos, os canais de comercialização utilizados pelos agricultores pesquisados são variados, destacando-se os seguintes: a) feiras livres; b) sacolões e mercados de bairro; c) supermercados; d) ponto de venda no próprio local da produção; e) venda de porta em porta; f) revenda em bancas de rua (seja diretamente pelo produtor, seja por ambulantes que adquirem os produtos dos produtores).

Elemento de suma importância para as diversas possibilidades de comercialização diz respeito à capacidade de consumo pela população urbana, como consequência do tamanho demográfico e do poder aquisitivo, permitindo a coexistência de estabelecimentos que focalizam públicos consumidores específicos. Em que pese, na atualidade, a crescente participação do setor de abastecimento alimentar controlado por grandes redes de capital nacional e internacional, o capital local, representado pelos sacolões e mercados de bairro, é fundamental para a compreensão da inserção de produtores hortícolas de pequena e média capacidade produtiva no abastecimento desses pontos comerciais de menor demanda.

A Figura 3 destaca os estabelecimentos prioritariamente dedicados à comercialização de hortifrútis (sacolões) ou com um setor para tal finalidade. Destacamos a predominância dos mercados de bairro, que foram classificados como tendo até quatro checkouts. 
Campos Neutrais - RevistaLatino-Americana de Relações Internacionais Vol. 1, No 2, p. 73-90, Maio - Agosto de 2019

FIGURA 3 - Presidente Prudente: estabelecimentos comerciais com setor de hortifrúti (2018)

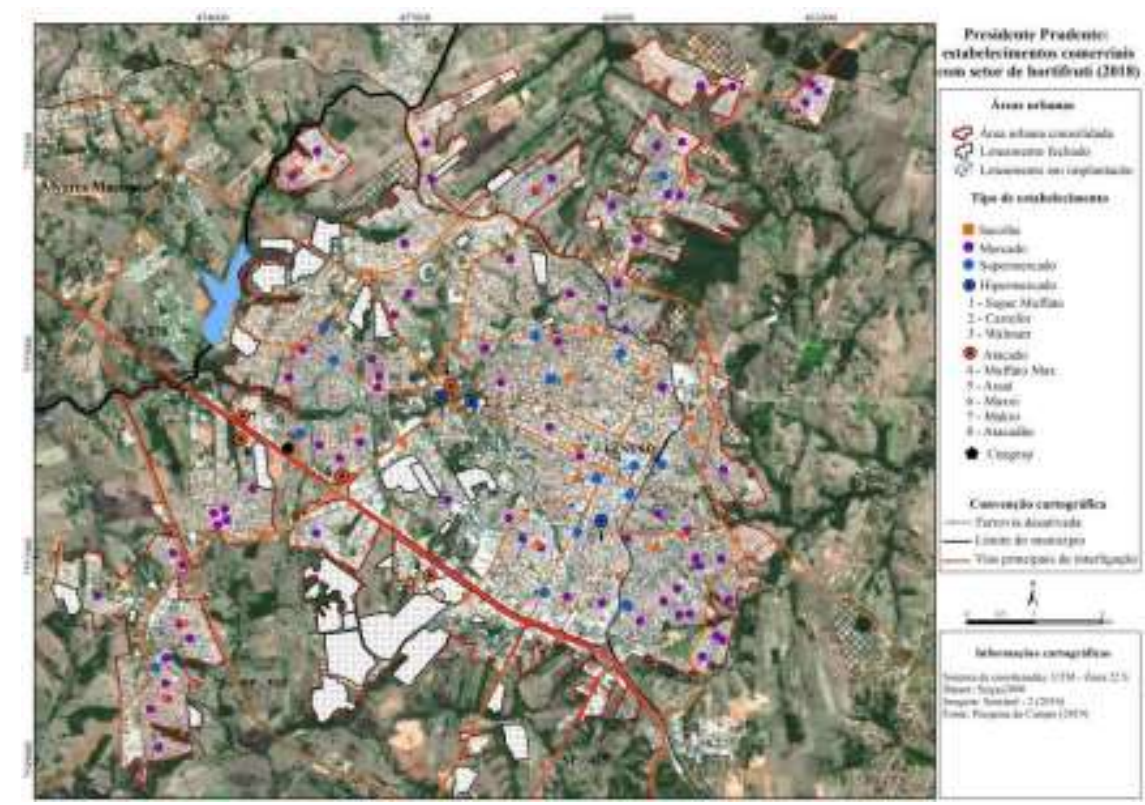

Fonte: Sistemas de Coordenadas UTM

Os supermercados são componentes fundamentais no abastecimento urbano, na medida em que têm inserção em diversas áreas da cidade; já os hipermercados e atacadistas, pela dimensão do estabelecimento, buscam localizações estratégicas visando consumidores de áreas mais abrangentes, ou seja, um raio maior de atuação. Por isso mesmo, impõem ao consumidor menor frequência semanal ou mensal, possibilitando que sacolões, mercados de bairro e supermercados absorvam uma parcela significativa da demanda por produtos de alta perecibilidade e de abastecimento mais frequente, tais como as hortaliças de folhagens.

Em Presidente Prudente há 28 feiras livres, significativas em termos de geração de postos de trabalho na comercialização dos produtos (incluindo os produtores das áreas urbana e periurbana), e também em razão da distribuição pelas diversas áreas da cidade onde, em determinado dia da semana, concorrem com os demais estabelecimentos na provisão de hortifrútis. Com base nos principais canais de comercialização utilizados pelos agricultores pesquisados, foi elaborada a Figura 4, que indica a localização das áreas de produção e os estabelecimentos e locais para onde são remetidos os produtos cultivados. 
Campos Neutrais - RevistaLatino-Americana de Relações Internacionais Vol. 1, No 2, p. 73-90, Maio - Agosto de 2019

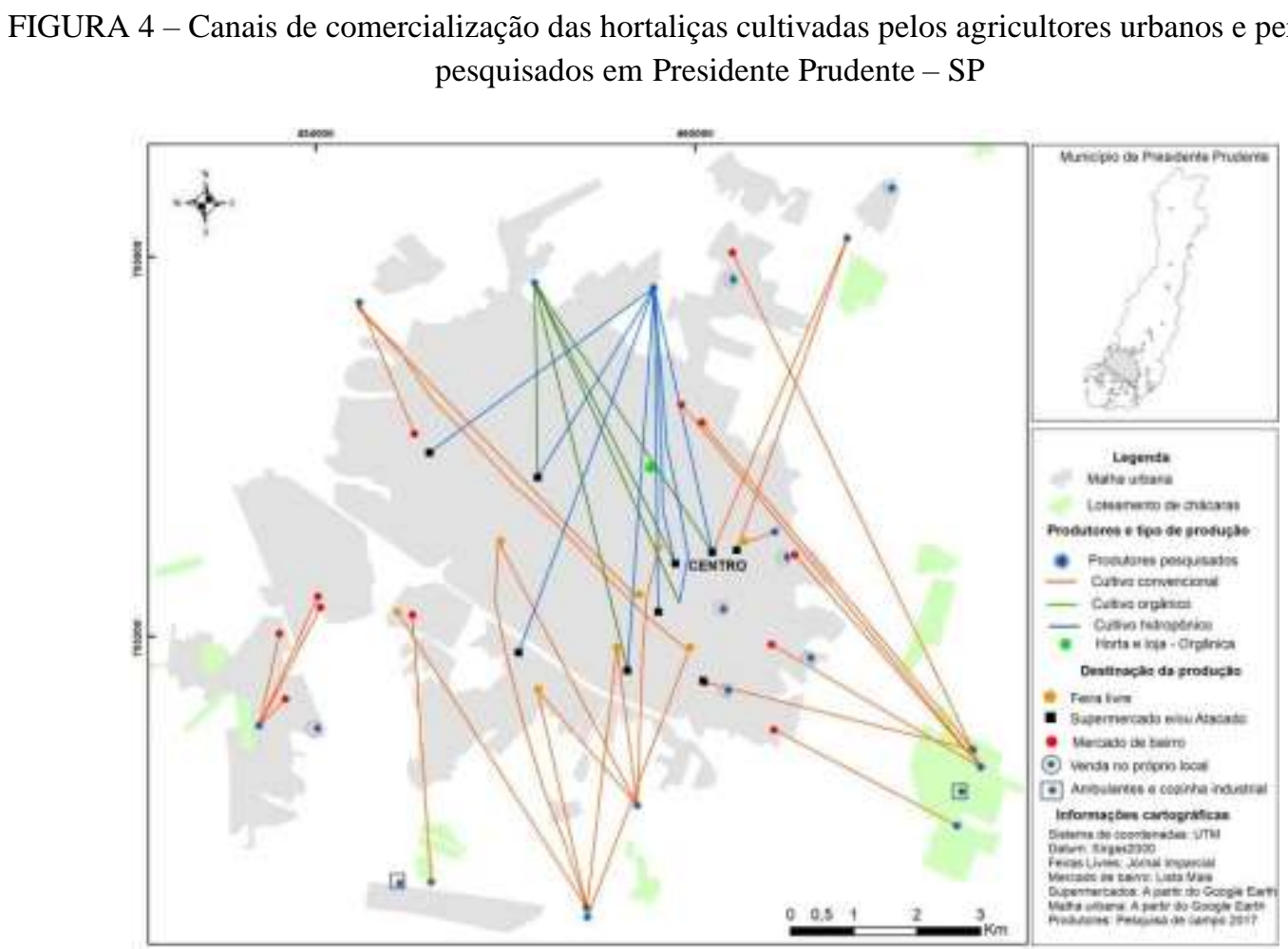

Fonte: Sistemas de Coordenadas UTM

Embora os pequenos mercados de bairro tenham reduzida capacidade de absorver a produção, não deixam de ser importantes para os produtores de hortaliças, em virtude de a negociação ser feita diretamente com os proprietários dos estabelecimentos, por seus departamentos de compras, diferentemente do que ocorre com os supermercados e hipermercados. Nestes, a negociação é feita com gerentes e encarregados das seções de hortifrutigranjeiros, e as empresas possuem maior poder para impor as condições, normalmente muito desfavoráveis aos produtores, além de parte dos itens serem provenientes de áreas distantes, visto a existência de centros de distribuição.

De acordo com os produtores pesquisados, uma das principais vantagens de vender aos mercados de bairro está no fato de os comerciantes pagarem à vista e assumirem eventuais prejuízos com os produtos que não são vendidos, o que não ocorre nos supermercados e hipermercados, aos quais devem repor as hortaliças que não foram comercializadas.

Além disso, os supermercados e atacadistas exigem a emissão de nota fiscal e a regularidade no fornecimento em quantidades expressivas durante todo o ano, sendo, portanto, menos acessíveis aos agricultores urbanos e periurbanos, que geralmente não são formalizados (não dispõem de notas fiscais para fornecer) e estão mais sujeitos à sazonalidade da produção, não podendo assumir o compromisso de fornecer os produtos com a 
Campos Neutrais - RevistaLatino-Americana de Relações Internacionais

Vol. 1, No 2, p. 73-90, Maio - Agosto de 2019

regularidade requerida pelas empresas de maior porte.

As vendas nos próprios locais de produção são realizadas majoritariamente nas hortas urbanas de pequeno porte, nas quais os moradores das imediações compram os produtos frescos diretamente dos agricultores.

\section{Considerações finais}

A AUP é um fenômeno comum e está presente na grande maioria das cidades, embora, no caso brasileiro, não seja apoiada por políticas públicas, nem contemplada nos planos urbanísticos e diretores das cidades e municípios.

Em Presidente Prudente foi instituído, em 1997, o Programa "Alimente Prudente", com a proposta de dar apoio a grupos de horticultores em áreas cujo uso foi concedido pelo poder público municipal. Desde o fim do Programa, em 2005, não há qualquer ação pública de apoio à AUP.

Mesmo assim, a AUP é expressiva no município e, conforme procurou-se demonstrar ao longo deste artigo, o fenômeno é bastante diverso em termos de dimensão das áreas cultivadas, condições de acesso à terra, tipos de áreas cultivadas, sistemas de produção adotados, produtos cultivados e canais de comercialização utilizados.

A maioria dos agricultores urbanos e periurbanos pesquisados cultiva em áreas inferiores a 2.000 metros quadrados, localiza-se em áreas periurbanas e realiza o cultivo em terrenos próprios ou pertencentes à família. Predomina o sistema convencional de cultivo, com a utilização de adubos orgânicos e químicos, além da aplicação esporádica de agrotóxicos.

Constatou-se que há forte predomínio do cultivo de folhosas, principalmente alface, couve, cebolinha e salsinha. Também são cultivadas hortaliças de frutos, raízes e tubérculos, com destaque para a mandioca e, em menor proporção, o chuchu, o rabanete e o quiabo. Os canais de comercialização utilizados são variados, como feiras livres, sacolões e pequenos mercados de bairro, além da venda direta aos consumidores, realizada nos próprios locais de produção e em domicílio.

A despeito da pressão exercida pelo mercado imobiliário e da falta de apoio e regulamentação públicos, a AUP é resiliente e importante para a geração de ocupação e renda das pessoas que a praticam. 
Campos Neutrais - RevistaLatino-Americana de Relações Internacionais

Vol. 1, No 2, p. 73-90, Maio - Agosto de 2019

\section{Referências}

LEITE, José Ferrari. A Alta Sorocabana e o espaço polarizado de Presidente Prudente. Presidente Prudente: FAFI, 1972.

MACHADO, A. T.; MACHADO, C. T. T. Agricultura urbana. Documentos /Embrapa Cerrados, 2002. Disponível em: http:bbeletronica.cpac.embrapa.br/2002/doc/doc_48.pdf acesso em 02 fev.2017.

MADALENO, I. M. Políticas de apoio à agricultura urbana em Lisboa e Presidente Prudente. Revista de Agricultura Urbana, n.4, 2001. Disponível em: http://www.agriculturaurbana.org.br/RAU/AU4/AU4lisboa.html. acesso em 28 out. 2017.

MOUGEOT, L. J. A. Agricultura Urbana - conceito e definição. Revista de Agricultura Urbana, n. 1, 2000. Disponível em: http://www.agriculturaurbana.org.br/RAU/AU1/AU1conceito.html. acesso em 28 out. 2017.

NASCIMENTO, Agnaldo da Silva. No vazio, caberiam casas, parques, fábricas... caberia muita cidade. Dissertação (Mestrado em Geografia) Faculdade de Ciências e Tecnologia, UNESP, Presidente Prudente, 2014.

SANTANDREU, Allain; LOVO, Ivana Cristina. Identificação e Caracterização de Iniciativas de Agricultura Urbana e Periurbana em Regiões Metropolitanas Brasileiras. In: Organização das Nações Unidas para a Agricultura e Alimentação - FAO; Ministério do Desenvolvimento Social e Combate à Fome - MDS; Secretaria de Segurança Alimentar e Nutricional SESAN; Departamento de Promoção de Sistemas Descentralizados - DPSD. Panorama da agricultura urbana e periurbana no Brasil e diretrizes políticas para sua promoção. Belo Horizonte, 2007.

SILVA, Clécio Azevedo da A instituição dos circuitos de proximidade no sistema alimentar: fatores de permanência e estratégias dos agentes. In: XIX Encontro Nacional de Geografia Agrária. São Paulo, 2009.

SPOSITO, Maria E. B; GÓES, Eda Maria. Espaços fechados e cidades: insegurança urbana e fragmentação socioespacial. São Paulo: Editora UNESP, 2013.

VALE, Ana Rute do. Expansão urbana e plurifuncionalidade no espaço periurbano do município de Araraquara (SP). Tese (Doutorado em Geografia) Instituto de Geociências e Ciências Extas, UNESP, Rio Claro, 2005.

VILLAÇA, Flávio. Espaço intra-urbano no Brasil. São Paulo: Editora Studio Nobel, 2001. 